Old Dominion University

ODU Digital Commons

Bioelectrics Publications

Frank Reidy Research Center for Bioelectrics

2012

\title{
The Use of an in vitro 3D Melanoma Model to Predict in vivo Plasmid Transfection Using Electroporation
}

Benadette Marrero

Richard Heller

Old Dominion University, rheller@odu.edu

Follow this and additional works at: https://digitalcommons.odu.edu/bioelectrics_pubs

Part of the Biomaterials Commons, Biomedical Commons, and the Molecular, Cellular, and Tissue Engineering Commons

\section{Repository Citation}

Marrero, Benadette and Heller, Richard, "The Use of an in vitro 3D Melanoma Model to Predict in vivo Plasmid Transfection Using Electroporation" (2012). Bioelectrics Publications. 205.

https://digitalcommons.odu.edu/bioelectrics_pubs/205

\section{Original Publication Citation}

Marrero, B., \& Heller, R. (2012). The use of an in vitro 3D melanoma model to predict in vivo plasmid transfection using electroporation. Biomaterials, 33(10), 3036-3046. doi:10.1016/j.biomaterials.2011.12.049

This Article is brought to you for free and open access by the Frank Reidy Research Center for Bioelectrics at ODU Digital Commons. It has been accepted for inclusion in Bioelectrics Publications by an authorized administrator of ODU Digital Commons. For more information, please contact digitalcommons@odu.edu. 


\title{
The use of an in vitro 3D melanoma model to predict in vivo plasmid transfection using electroporation
}

\author{
Bernadette Marrero ${ }^{\mathrm{a}}$ and Richard Heller ${ }^{\mathrm{a}, \mathrm{b},{ }^{*}}$ \\ aDepartment of Molecular Medicine, University of South Florida, Tampa, FL 33612, USA \\ ${ }^{\mathrm{b}}$ Frank Reidy Center for Bioelectrics Old Dominion University, Norfolk, VA 23508, USA
}

\section{Abstract}

\begin{abstract}
A large-scale in vitro 3D tumor model was generated to evaluate gene delivery procedures in vivo. This 3D tumor model consists of a "tissue-like" spheroid that provides a micro-environment supportive of melanoma proliferation, allowing cells to behave similarly to cells in vivo. This functional spheroid measures approximately $1 \mathrm{~cm}$ in diameter and can be used to effectively evaluate plasmid transfection when testing various electroporation (EP) electrode applicators. In this study, we identified EP conditions that efficiently transfect green fluorescent protein (GFP) and interleukin 15 (IL-15) plasmids into tumor cells residing in the 3D construct. We found that plasmids delivered using a 6-plate electrode applying 6 pulses with nominal electric field strength of $500 \mathrm{~V} / \mathrm{cm}$ and pulse-length of $20 \mathrm{~ms}$ produced significant increase of GFP (7.3-fold) and IL-15 (3.0-fold) expression compared to controls. This in vitro 3D model demonstrates the predictability of cellular response toward delivery techniques, limits the numbers of animals employed for transfection studies, and may facilitate future developments of clinical trials for cancer therapies in vivo.
\end{abstract}

\section{Keywords}

3D tumor model; Melanoma; Electroporation; Gene transfer; Bioreactor

\section{Introduction}

\begin{abstract}
Many forms of in vitro three dimensional (3D) tumor models have been generated to address how co-cultured cells behave compared to cells residing together in vivo [1-3]. Investigations have examined whether immortalized cell lines coaxed into a 3D environment are able to preserve natural functions when grown as homo- or heterogeneous populations $[4,5]$. In addition, the models may be used to determine appropriate parameters to translate non-viral gene delivery methods in vivo. Wasungu et al., analyzed the permeability of cells subjected to electroporation (EP) when organized on a synthetic matrix forming a microscale 3D construct [6]. This group demonstrated an increase in the permeabilization of layered cells when exposed to electric fields, suggesting a good model for testing gene delivery techniques in vivo [7]. These studies raise two questions: (1) do complimenting cell types such as keratinocytes and melanoma cells co-inhabiting an in vitro 3D construct cross talk and promote functional activities similar to in vivo micro-environments and (2) can a
\end{abstract}

(C) 2012 Elsevier Ltd. All rights reserved.

"Corresponding author. Frank Reidy Research Center for Bioelectrics Old Dominion University, Norfolk, VA 23508, USA. Tel.: +1 757683 2690; fax: +1 757451 1010. rhellerodu.edu (R. Heller).

Appendix. Supplementary material

Supplementary material associated with this article can be found, in the online version, at doi:10.1016/j.biomaterials.2011.12.049. 
large-scale 3D tumor model predict the transfection efficacy of particular plasmids delivered with various EP conditions prior to testing them in pre-clinical animal models? To address these questions, we analyzed how keratinocytes and melanoma cells mutually interact within a functional 3D construct and how this model translates potential anti-tumor gene delivery techniques in vivo.

Normally, keratinocytes (epidermal cells) and melanocytes (melanin producing cells) are known to cross talk with one another in nature through cell-cell contact, adhesive properties and growth factors. Ultraviolet exposure stimulates melanin production in melanocytes to protect keratinocytes against DNA damage [8]. Melanocytes themselves can undergo many aberrant genetic alterations either spontaneously or due to UV rays, which in turn may upregulate oncogenic properties and enhance tumor expansion [9]. Keratinocytes are known to act in a tumor suppressive manner by enhancing integrins and adherent proteins such as Ecadherin during early stages of aggressive human melanoma development. Keratinocytes function to prevent tumor cells from migrating into deeper layers of the epidermis, while melanoma cells can escape these suppressive signals by down-regulating E-cadherin and upregulating melanoma adhesion receptors $[10,11]$. The melanoma cell's tumorigenic evasion signals help dissociate keratinocyte integrins and adherent proteins, breaking the cross talk capabilities $[8,12,13]$. Previously published studies have demonstrated that these cells types require one another's functional properties to maintain a homeostatic environment, which suggests compatible co-existence with in a 3D model.

The 3D model described here was previously generated in a bioreactor [14]. Human keratinocyte (HaCaT) aggregates were formed in a high aspect ratio vessel (HARV) producing a "tissue-like" scaffolding which supported viable proliferation and differentiation of melanoma (B16.F10) cells [14]. HaCaT cells were utilized to mimic naturally occurring keratinocytes, a major component of the basal layer within the epidermis which houses melanocytes $[8,15]$. In this previous study, $\mathrm{HaCaT}$ and B16.F10 cells were able to coexist in the 3D model and actively undergo different mitotic phases of the cell cycle; this was demonstrated by varying degrees of nuclear staining using a Ki67 proliferation marker. In addition, both cell types demonstrated the production of their own extracellular matrix (ECM), detected by fibronectin staining. ECM provides structural support of cells and makes up the basement membrane where epithelial cells reside $[14,16-$ 18]. Additional studies indicate that cells grown in a 3D micro-environment may imitate natural cellular functions more closely then cells grown as a monolayer in culture [19-21].

The purpose for generating this in vitro 3D tumor model was to identify EP parameters that effectively deliver plasmid DNA into cultured cells. One important feature of the 3D tumor model is the size of the spheroid, which measures approximately $1 \mathrm{~cm}$ in diameter [14]. This is ideal for adapting in vitro EP parameters to predict effective EP conditions for in vivo plasmid delivery. EP enhances transfection of naked DNA into a large number of cell and tissue types [22]. Transfection of particular cells requires the optimization of the applied voltage (nominal electric field strength), pulse width, pulse frequency and the use of the appropriate EP electrode applicator. Important concepts to consider with respect to delivering genes of interest into the 3D model with the electrode applicators include tissue type, location (surface or internal location) and size of the area to be treated. The ability to evaluate effective delivery using an in vitro large-scale 3D model prior to testing conditions in vivo is currently unavailable and would be beneficial for optimizing various EP conditions on different cell and tissue types. The identification of efficient non-viral gene delivery methods in vitro would reduce utilization of preclinical animal models prior to translating EP procedures in vivo. 


\section{Materials and methods}

\subsection{Materials}

Human HaCaT keratinocytes were provided as a generous gift from Dr. Mark Jaroszeski University of South Florida College of Engineering. Mouse melanoma B16.F10 and human melanoma SKMEL-5 were purchased from the American Type Culture Collection (Manassas, VA). Human interleukin 15 plasmid (phIL-15) was a generous gift provided by Dr. David B. Weiner University of Pennsylvania College of Medicine. Green Fluorescent Protein plasmid pEGFP-N1 (GFP) was purchased from Clontech (Palo Alto, CA). All plasmids were commercially prepared by Aldevron (Fargo, ND).

\subsection{D spheroid construct}

As previously described [10], 3-5 $310^{6}$ cells of HaCaT were seeded into four T275 flasks grown in DMEM (Media Tech Manassas, VA) containing 0.2\% gentamycin (MidSci, St. Louis, MO), and 10\% Fetal Bovine Serum (FBS) (Atlanta Biologicals, Lawrenceville, GA). After 2-3 days, confluent cells were trypsinized with $1 \times$ trypsin without EDTA (Atlanta Biologicals, Lawrenceville, GA) and viability was determined using trypan blue staining. On Day $0,35-50 \times 10^{6}$ live HaCaT cells were seeded into $10 \mathrm{~mL}$ HARVs (Synthecon, Inc., Houston, TX). The silicon membrane covering one half of the HARV allows for passive diffusion of oxygen to support cell viability and proliferation. The rotation of the HARV is varied dependent on the size and shape of the spheroid in order to maintain a state of freefall or solid body rotation under a 1 -g-force environment. HaCaT cells were initially rotated at 15.0-16.5 rpm using the RCCS-4SCQ system for 8-12 $\mathrm{h}$ and then increased to 18.0-20.0 $\mathrm{rpm}$. This process produces spheroids that are $0.75-0.95 \mathrm{~cm}$ in diameter. After $20-24 \mathrm{~h}$, fresh DMEM was replaced in the HARVs containing aggregated $\mathrm{HaCaT}$ cells. In parallel, B16.F10 cells were grown in McCoy's media and SKMEL-5 were grown in MEM, both containing $0.2 \%$ gentamycin and 10\% FBS, separately in two T275 flasks. Upon confluence, $1-2 \times 10^{6}$ cells were harvested and then injected into 2 day old $\mathrm{HaCaT}$ spheroids and used for EP procedures.

\subsection{TdT and immunohistochemistry (IHC) assay}

The TdT-FragEL DNA Fragmentation Detection assay (Calbiochem, San Diego, CA) was performed on paraffin embedded samples to identify cells undergoing cell death followed by a double IHC staining to specifically differentiate apoptotic cells from viable cells. The assay was performed per manufacturer's instructions; a positive and negative control was performed simultaneously with the assay. For the positive control, DNAse I (Promega, Madison WI) was used to intentionally nick the DNA ends; the negative control was deficient of the TdT reaction mix. Briefly, the samples on the slide were deparaffinized in xylene and rehydrated by immersing slides in different concentrations of ethanol (SigmaAldrich St. Louis, MO). The sections were permeabilized using 1:100 $2 \mathrm{mg} / \mathrm{ml}$ Proteinase K (Thermo Sci Waltham, MA) in $10 \mathrm{mM}$ Tris $\mathrm{pH} 8$, then blocked with $30 \%$ hydrogen peroxide (Thermo Scientific, Waltham, MA) in methanol (Sigma-Aldrich, St. Louis, MO). The sections were labeled with TdT labeling reaction mix, conjugated with Strep-HRP and developed by 3,3' Diaminobenzidine (DAB) solution. For double IHC staining, 1:200 primary mouse anti-human AE1/AE3 antibody was diluted in 2.5\% normal goat serum (Molecular Probes, Carlsbad CA), while secondary goat anti-mouse IgG AP was diluted in 1:50 goat serum. All slides were developed using Fast Red (Thermo Scientific, Waltham, MA). Sections were incubated with 1:100 primary antibody S100 goat anti-mouse (sc-7849 Santa Cruz Biotech, Santa Cruz CA) diluted in 2.5\% rabbit serum (Molecular Probes, Carlsbad CA). The sections were incubated with 1:20 secondary rabbit anti-goat IgG HRP (HAF017 R\&D Systems, Minneapolis MN) in rabbit serum and developed using DAB. All sections were counterstained with methyl green, mounted using Permount (Fisher, 
Pittsburgh PA) and then observed under a light microscope. The methyl green counter-stain produced a tan or blue-green stain for viable cells and DAB stained the nucleus dark brown to signify cells had undergone pseudo-apoptosis. Viable cells were counted using an ocular lens micrometer at 200× Magnification (Mag.) [10].

\subsection{Plasmid delivery to 3D spheroid}

Stable spheroids were removed from the HARV after $48 \mathrm{~h}$ and placed into a chamber slide. The fluid-filled, malleable spheroid laid convex on the chamber slide and was then coated with about $500 \mu \mathrm{l}$ of fresh DMEM (Atlanta Biologicals, Lawrenceville, GA) which was sufficient to maintain the spheroid in liquid during the injection and EP procedure. A 25gauge 5/8 inch needle attached to a $1 \mathrm{~mL}$-syringe (BD Biosciences, Franklin Lakes, NJ) was used to inject $50 \mu \mathrm{l}$ containing $3-5 \times 10^{6}$ B16.F10 in McCoy's media or SKMEL-5 in MEM media and $1.0 \mathrm{mg} / \mathrm{ml}$ of pEGFP-N1 or phIL-15. The needle was inserted into the spheroid to a depth of 3-5 $\mathrm{mm}$ from the surface towards the center. This was a single point injection with sufficient volume and placement to ensure equal delivery of cells and plasmid within the spheroid. The EP electrodes were situated so that the injection site was in the center of the array. The spheroids were electroporated with different electrode arrays with varying characteristics (Table 1). These specific arrays were chosen to simulate how electroporation would be applied in vivo. The non-penetrating arrays are typically utilized to deliver plasmid DNA to skin while penetrating arrays are typically utilized for tumors and muscle among other tissues [22]. The 6-needle array has been used for delivery of plasmids to tumors. The electrodes are typically inserted into the skin surrounding the tumor. Since this was not possible with the spheroid, a six-plate electrode (6-PE) was used and the electrodes were placed against the sides of the spheroid. Previous studies have demonstrated that rotating the field around the array can enhance delivery [23,24]. Therefore for each of the arrays, the pulses were administered in different directions. For the 6-PE and 6-needle array, the pulses are applied between 4 of the 6 electrodes (forming a rectangle) and each pulse is applied in a direction that is 60 degrees from the previous one [24]. Thus, after 6 pulses, a full $360^{\circ}$ rotation is completed. For the $4 \mathrm{PE}, 4$ pulses are applied across two plates then an additional 4 pulses applied across the 2 perpendicular plates. For the 4 -needle array, three pulses are applied in each of four directions. First, pulses are applied across the $2.5 \mathrm{~mm}$ gap, then across each diagonal, and then finally across the $5 \mathrm{~mm}$ gap for a total of 12 pulses. The applied voltage is based on the gap between the electrodes to achieve the desired nominal field strength $(\mathrm{V} / \mathrm{cm})$. The electrode arrays were placed into (penetrating) or around (nonpenetrating) the tissue of interest. To administer the voltage, a BTX830 square-pulse wave direct current generator was utilized. After EP was complete, 1-2 mL of 70\% McCoy's + $30 \%$ DMEM or $30 \%$ MEM complete media was added to the chamber slide, covered and placed into a $1.5 \% \mathrm{CO}_{2} 37{ }^{\circ} \mathrm{C}$ humidified incubator. The spheroids were monitored and harvested $24-48 \mathrm{~h}$ after transfection for analysis.

\subsection{Western blots}

Ready-gels (4\%-15\%) and transfer blot apparatus (Biorad Hercules, CA) were used to detect protein markers E-cad (MAB3199Z, Millipore, Billerica, MA), Cyto-8 (sc-8020, Santa Cruz Biotech, Inc., Santa Cruz, CA) and Beta Actin (\#4967, Cell Signaling, Danvers, MA). Tumor lysate proteins were separated using 110V-120V. Immobilon PVDF Membrane and detection reagents were purchased from LI-COR Biosci (Lincoln, NE). Proteins were transferred onto the membrane at $110 \mathrm{~V}$ and blocked with blocking buffer. The membrane was incubated with primary antibody at 1:2000 (E-cad) or 1:500 (Cyto-8) on a shaker, at room temperature overnight. After 16-18 h, 1:15,000 0.5 mg goat anti-mouse IR Dye 800CW NHS Ester was added as a secondary antibody. An Odyssey Infrared Imaging System (LI-COR Biosci, Lincoln, NE) was used to detect fluorescently labeled bands. Stripping reagent was used between different primary antibodies. Protein bands were 
normalized against 1:5000 Beta Actin (Cell Signaling Danvers, MA). The expression of proteins were analyzed against positive control MCF-7 human breast cancer cell line, which is known to express both human Cyto-8 and E-cad, while negative control B16.F10 does not express human Cyto-8 or E-cad.

\subsection{Stereoscope analysis}

Following formation of HaCaT spheroids (Day 2), both pEGFP-N1 and B16.F10 cells were injected into spheroids and immediately electroporated with the 6-PE using different electroporation parameters (see results). An Olympus BX51 microscope and a Leica MZFLIII Stereoscope with digital cameras were used to analyze GFP protein expression in spheroids.

\subsection{Immunofluorescence staining}

Spheroids were collected at 24-48 h, snap-frozen and cryo-sectioned. Samples were labeled with 1:1000 DAPI (Sigma-Aldrich, St. Louis, MO) to visualize all cells, blocked with $2.5 \%$ chicken serum (Thermo Scientific, Waltham, MA), incubated with primary antibody 1:100 AE1/AE3 (MAB3412 Millipore, Billerica, MA) and then incubated with 1:100 secondary antibody chicken anti-mouse IgG Rhodamine (sc-2861, Santa Cruz Biotech, Inc., Santa Cruz, CA) on shaker at room temperature. Sections were analyzed for GFP expression using an Olympus BX51 microscope at 200× Mag.

\subsection{Flow cytometry}

Spheroid aggregates were pressed through a $40 \mu \mathrm{m}$ Nylon cell strainer (BD Biosciences, Bedford, MA) and viability was determined using trypan blue exclusion (Fisher Scientific, Pittsburg, PA). For detection of live/dead cells, $1-3 \times 10^{6}$ cells were incubated with $10 \mu \mathrm{l}$ of propidium iodide (Immuno Chemistry Technologies, Bloomington, MN) for 30 mins and then sampled using the FACS Aria I (BD Biosciences, San Jose, CA) to quantitate GFP expression between groups.

\subsection{In vivo intratumoral delivery}

Female, 6-8 week-old C57BL/6 mice (Jackson Laboratories, Bar Harbor, ME) were inoculated subcutaneously in the left flank with $50 \mu$ of $1 \times 10^{6}$ B16.F10 cells. After 6-10 days, tumors ranged from 30 to $60 \mathrm{~mm}^{3}$. Tumor size was measured using calipers and calculated by $\mathrm{V}=\mathrm{ab}^{2} \pi / 6$ : (a) longest diameter and (b) shortest diameter. Mice were anesthetized by placing animals into an induction chamber infused with a mixture of $3 \%$ isoflurane and $97 \%$ oxygen. Anesthesia was maintained during the procedures using a rodent mask. Mice received a single injection of $1.0 \mathrm{mg} / \mathrm{ml} \mathrm{phIL-15}$ at a volume of $50 \mu \mathrm{l}$ directly into the tumor and pulses were immediately administered using a 6-needle array placed around the tumor (inserted into the skin surrounding the tumor). Six pulses with a pulse width of $100 \mu \mathrm{s}$ and a nominal field strength of $1300 \mathrm{~V} / \mathrm{cm}(1196 \mathrm{~V}$ applied) or with a pulse width of $20 \mathrm{~ms}$ and a nominal field strength of $500 \mathrm{~V} / \mathrm{cm}$ (460 V applied) were applied. All samples were collected after $12 \mathrm{~h}, 18 \mathrm{~h}, 24 \mathrm{~h}$ and $48 \mathrm{~h}$; snap frozen and stored at $-80{ }^{\circ} \mathrm{C}$ until processed for ELISA.

\subsection{In vivo intradermal delivery}

C57BL/6 mice received a single injection of $50 \mu \mathrm{lphIL}-15$ administered intra-dermally and pulses were immediately administered using the 4-PE placed around the injection site. Since a $50 \mu \mathrm{l}$ intradermal injection raises a $6 \mathrm{~mm}$ bubble in the skin, the 4-PE is designed with a 6 $\mathrm{mm}$ gap between electrodes to fit around this bubble. A total of 8 pulses (4 pulses in each of two perpendicular directions) were administered at two different sets of electroporation parameters:(1) a pulse width of $150 \mathrm{~ms}$ at a nominal field strength of $100 \mathrm{~V} / \mathrm{cm}(60 \mathrm{~V}$ 
applied) or (2) a pulse width of $20 \mathrm{~ms}$ at a nominal field strength of $200 \mathrm{~V} / \mathrm{cm}(120 \mathrm{~V}$ applied). All samples were collected after $12 \mathrm{~h}, 18 \mathrm{~h}, 24 \mathrm{~h}$ and $48 \mathrm{~h}$; snap-frozen and stored at $-80^{\circ} \mathrm{C}$ until processed for ELISA.

\subsection{ELISA}

Monoclonal human IL-15 Quantikine kit (R\&D Systems Minneapolis, MN) was performed following the manufacturer's instructions. Briefly, the frozen spheroids, tumor or skin were collected, weighed, and homogenized in 500 $\mu \mathrm{l}-600 \mu \mathrm{l}$ Phosphate Buffered Saline (EMD Biosciences, Darmstadt, Germany) plus Protease Inhibitor Cocktail (Roche, Branford, CT). The homogenate was centrifuged at $1000 \mathrm{rpm}$ for $5 \mathrm{~min}$ at $4{ }^{\circ} \mathrm{C}$ and the supernatant was assayed the same day.

\subsection{Statistical analysis}

The results were analyzed using SPSS (IBM Chicago, IL) one-way ANOVA with post-hoc least square difference test. Analysis was based on the means and standard deviation of 4 or 12 independent experiments depending on the assay.

\section{Results and discussion}

\subsection{Stability of 3D model construct}

$\mathrm{HaCaT}$ cells $\left(50 \times 10^{6}\right.$ cells) were injected into the bioreactor and aggregated into approximately $1 \mathrm{~cm}$ diameter "tissue-like" construct after $24 \mathrm{~h}$. The HARV was initially set to rotate at $15.0-16.5 \mathrm{rpm}$, and 8-12 h later the rotation of the HARV was increased to 18.0$20.0 \mathrm{rpm}$, which promoted a stable solid body rotation with minimal bouncing. The HARV allows cellular growth in a microgravity environment through the use of solid body rotation. Placing the cells in this environment facilitated aggregation of the cells into a spheroid. The rotation of the HARV is such that the spheroid is in a constant free-fall, essentially floating in place, keeping it away from the walls of the HARV while the media rotates around with minimal interference and shear. The HARV's constant rotation stabilized the 3D construct within $48 \mathrm{~h}$; this stability time point was determined by observations of $\mathrm{HaCaT}$ spheroid formation for up to 15 days (d). After $48 \mathrm{~h}$, HaCaT spheroids were injected with $2-3 \times 10^{6}$ mouse B16.F10 melanoma or human SKMEL-5 melanoma cells. At 4-6d post inoculation, both B16.F10 and SKMEL-5 spheroids demonstrated a heterogeneous population of both cell types (Fig. 1a) [10]. A TdT viability analysis was performed on paraffin sections of the SKMEL-5 cells (Fig.1b). to complement the viability assay previously performed on the B16.F10 cells analyzed in Marrero et. al To further identify SKMEL-5, cells were detected with an HRP conjugated antibody that stained surface marker S100 brown, while $\mathrm{HaCaT}$ cells stained red, detected by an AP conjugated antibody specific for the AE1/3 surface marker. Nuclei, stained tan in viable cells; apoptotic nuclei stained dark brown. Greater than $80 \%$ of SKMEL- 5 cells remained viable after $6 \mathrm{~d}$, comparable to the results obtained from the TdT assay performed on B16.F10 in the previous study [10]. Additionally, using trypan blue staining we observed that $\mathrm{HaCaT}$ spheroid aggregates residing alone in the HARV reached terminal differentiation after 5-7d. Multiple experiments and observations confirmed that HaCaT spheroids injected with melanoma remained stable in the HARV and for up to $15 \mathrm{~d}$.

\subsection{Demonstration of cross talk between cells in 3D tumor model}

The expression of differentiation marker cytokeratin 8 (Cyto-8) and adherent protein marker E-cadherin (E-cad) were analyzed to confirm cross talk between two different cell populations coexisting in a 3D culture. Cyto- 8 and E-cad proteins are produced by both mouse and human keratinocytes $[25,26]$. Cyto- 8 functions to maintain structural integrity, 
indicates epithelial differentiation and characterizes malignancy of tumors [27], while E-cad up-regulates the adherent properties in keratinocytes and melanocytes as well as cancerous cells like melanoma $[8,12,28-30]$. We analyzed expression levels of cyto- 8 and E-cad by western blot analysis $2-4 \mathrm{~d}$ after inoculation (Fig. 1c). All band intensities were compared to the $\mathrm{HaCaT}$ only group and all protein expression was compared to the MCF-7 human breast cancer cell line, which is known to express both human Cyto- 8 and E-cad. The mouse proteins of the B16.F10 cells do not cross react with human Cyto- 8 or E-cad antibodies and served as a negative control. The Cyto- 8 differentiation marker presented consistently low band densities, <1-fold in groups HaCaT + B16.F10 and HaCaT+SKMEL-5 compared to $\mathrm{HaCaT}$ alone on days 2 and 4, suggesting that the decrease of Cyto- 8 resulted from the reduced $\mathrm{HaCaT}$ terminal differentiation while in the presence of melanoma [31-33]. Furthermore, we observed a 2.3-fold increase of adhesion protein E-cad in $\mathrm{HaCaT}+$ B16.F10 on Day 2 and 1.9-fold increase on Day 4. However, there was a slightly lower level of E-cad <1-fold in HaCaT+SKMEL-5 on Day 2 and 4. Studies have shown that SK-MEL5 produce less than normal levels of E-cad even in the presence of keratinocytes [8,30,33]. Therefore, SK-MEL5 cells act as a negative control for E-cad expression. We also observed that the HaCaT spheroid remained stable while in the presence of B16.F10 expansion for up to 15 days [10]. Therefore, Fig. 1c supports that a slight decrease in Cyto- 8 from group $\mathrm{HaCaT}+$ melanoma compared to $\mathrm{HaCaT}$ is observed and suggests that actively proliferating melanoma cells retard $\mathrm{HaCaT}$ terminal differentiation and increase E-cad, helping to maintain the structural integrity of the spheroid for up to 15 days [10,32]. We also observed that both proteins were readily up-regulated on day 2 compared to day 4 in all groups, suggesting that protein production was regulated by keratinocytes during early stages of melanoma growth. These data support the conclusions in our previous study, where we found that B16.F10 cells produce dendrite-like appendages during the immunofluorescence analysis, indicating the potential for cross talk between HaCaT and B16.F10 [10].

\subsection{Analyzing plasmid delivery and differences in expression}

To evaluate the applicability of the in vitro 3D model to in vivo gene transfer approaches, we delivered a pEGFP-N1 into HaCaT spheroids using different EP conditions, then $24 \mathrm{~h}$ later GFP protein expression was analyzed using a fluorescent Leica MZFLIII stereoscope (Fig. 2). A 4-needle electrode array, a 4-PE array or a 6-PE array were utilized to test several sets of EP conditions on the epidermal-like HaCaT cells [34]. We observed low GFP expression levels following delivery of pEGFP-N1 into the HaCaT spheroid using the 4needle array and EP parameters originally designed for muscle delivery; with this array [34], twelve $20 \mathrm{~ms}$ pulses administered in multiple directions at a nominal field strength of $100 \mathrm{~V} /$ $\mathrm{cm}$ (Fig. 2a,b). Low expression was also observed following delivery with the 4-PE utilizing EP parameters designed for skin delivery [23]. For these pulses, two sets of four pulses were delivered in perpendicular directions. Either $150 \mathrm{~ms}$ pulses at a nominal field strength of 100 $\mathrm{V} / \mathrm{cm}$ or $20 \mathrm{~ms}$ pulses at a nominal field strength of $200 \mathrm{~V} / \mathrm{cm}$ were applied (Fig. 2c). Both combinations of electrode and pulse parameters demonstrated low GFP intensity and distribution amongst cells located near the surface of the spheroid or near the site of electrode placement (Fig. 2b,c). We then tested delivery techniques using the 6-PE utilizing EP parameters previously established to deliver to tumors in vivo. Six, $100 \mu$ s pulse width with a nominal field strength of $1300 \mathrm{~V} / \mathrm{cm}$ (HVSP High Voltage Short Pulses) or six $20 \mathrm{~ms}$ pulse width with a nominal field strength of $500 \mathrm{~V} / \mathrm{cm}$ (LVLP Low Voltage Long Pulses) were applied [35]. Low levels of expression were observed following delivery of pEGFP-N1 into spheroids containing only $\mathrm{HaCaT}$ cells. To determine if the low levels of expression was specific for $\mathrm{HaCaT}$ cells, the procedure was modified by mixing $1.0 \mathrm{mg} / \mathrm{ml}$ pEGFP-N1 and B16.F10 together, then simultaneously injecting the mixture into the HaCaT spheroid, followed immediately by EP using the 6-PE. Interestingly, an increase in GFP levels was observed compared to the HaCaT spheroid alone (Fig. 2d,e). Higher expression was 
observed in melanoma cells than the keratinocytes within the spheroid. The administration of plasmid + B16.F10 + EP together enhanced GFP production and distribution in vitro. Differences in transfection levels were identified when delivering pEGFP-N1+B16.F10 with the two sets of EP parameters. In the spheroids receiving HVSP pulses (Fig. 2d), expressing cells were concentrated in two small locations near the injection site, while in the spheroids that received pulses with LVLP parameters, many more cells were transfected at the point of injection and throughout the spheroid where B16.F10 cells were located (Fig. 2e-g). It is important to note that the spheroid remained stable during the EP procedure as well as after the procedure for up to $24-48 \mathrm{~h}$. These time frames allowed sufficient time to analyze the effectiveness of EP delivery.

\subsection{Evaluating pEGFP-N1 delivery and GFP protein distribution}

To confirm which cell types were transfected with pEGFP-N1, spheroids were collected 24 $\mathrm{h}$ after EP and cryo-sectioned for fluorescent imaging. We observed higher levels of GFP expression and distribution in the LVLP group compared to the HVSP group utilizing the 6PE (Fig. 3a-f). The images show that spheroids electroporated with LVLP (Fig. 3a) expressed higher levels of GFP throughout the spheroid, towards the center and within loosely suspended B16.F10 cells injected into of the spheroid (Fig. 3b-c). Spheroids electroporated with HVSP (Fig. 3d) produced higher expression than the $100 \mathrm{~V} / \mathrm{cm}$ and 200 V/cm groups in Fig. 2a-c, but fewer cells were transfected (Fig. 3e-f). Expression was observed mainly at the site of injection. We also observed that B16.F10 cells were more readily transfected with a lower electric field $500 \mathrm{~V} / \mathrm{cm}$ and longer pulses $20 \mathrm{~ms}$ compared to higher electric field $1300 \mathrm{~V} / \mathrm{cm}$ with shorter pulses $100 \mu \mathrm{s}$. In this model, utilizing a lower electric field and longer pulse width resulted in higher expression. In addition, it is highly probable that applying the electric field over a larger area, for example $0.8 \mathrm{~cm}-1 \mathrm{~cm}$, resulted in delivery of plasmid DNA to more cells at one time. Utilizing an applicator such as the 6-PE allowed for even rotation of the field encompassing multiple directions. The amplitude of the applied voltage needed to permeabilize a cell membrane is inversely proportional to the radius of the cell. Since cells are not spherical, the direction of the field could expose either a long or short radius of the cell, therefore, by rotating the field increases the chance of exposing the long axis of the cell to the field and increasing the chance of inducing permeabilization $[6,7,22-25,34,35]$. The results obtained in this study confirmed that specific EP conditions and applicators are required to achieve desired delivery and subsequent expression between varying cell types such as $\mathrm{HaCaT}$ and B16.F10.

\subsection{GFP differential expression between $\mathrm{HaCaT}$ and B16.F10}

To evaluate GFP distribution more closely, we used additional fluorescent labels to analyze GFP expression using the LVLP conditions (Fig. 4a). The nuclei of cells were labeled with DAPI, which emits a blue signal when excited by a mercury lamp, and the HaCaT cells were labeled with rhodamine conjugated cyto-keratin AE1/3 antibody, which emitted a red signal, for contrast. The negative control slides showed no auto-fluorescence emitted from cells in the FITC (Fig. 4b) or TRITC (Fig. 4c) channels. The sample slides showed specific GFP expression in the FITC channel (Fig. 4d) and specific rhodamine labeled $\mathrm{HaCaT}$ in the TRITC channel (Fig. 4e). The DAPI and FITC channels merged together demonstrated the location of GFP expression amongst all cells (Fig. 4f). While merging the FITC and TRITC channels, demonstrated specific GFP expression between different cells types. The red fluorescing $\mathrm{HaCaT}$ cells co-localized with green GFP to produce an orange fluorescence, indicating that $\mathrm{HaCaT}$ cells were transfected. Cells that emitted exclusively green indicated only melanoma cells were transfected with pEGFP-N1 (Fig. 4g,h). Merging the FITC, TRITC and DAPI channels showed localization of all cells compared to pEGFP-N1 transfection (Fig. 4i,j). Based on these observations, many more melanoma cells than keratinocytes expressed GFP. 


\subsection{GFP quantitation}

Flow analysis was utilized to quantitate GFP expression levels between four groups. All four groups received an injection of pEGFP-N1 and were further divided as follows: 1) HaCaT cells (no EP), 2) B16.F10 cells (no EP), 3) HaCaT + B16.F10 + EP HVSP and 4) HaCaT + B16.F10 + EP LVLP. Samples were collected $24 \mathrm{~h}$ after delivery was performed to spheroids and processed by flow analysis on the same day (Fig. 5). This experimental procedure was performed four times. Population gates were drawn around live $\mathrm{HaCaT}+$ B16.F10 cells measuring 100,000 events (Fig. 5a), the H-gate was drawn to exclude propidium iodide stained dead cells and include the unstained live cells. A quadradic-gate was used to distinguish between positive and negative GFP expressing populations (Fig. 5b). A histogram plot was statistically analyzed using FlowJo software for Mean Fluorescent Intensities (MFI). GFP MFI levels for HaCaT + B16.F10 + EP HVSP and LVLP groups were 4.2-fold and 6.8-fold respectively higher than HaCaT control (Fig. 5c,d). The LVSP group resulted in 1.6-fold higher GFP expression than the HVSP groups (Fig. 5 and Supplementary Material Online Fig. 1). Evaluation of the mean MFIs from the four independent experiments showed that HaCaT + B16.F10 transfected with HVSP expressed GFP 3.2-fold higher and LVLP expressed a significant 7.3-fold more GFP than HaCaT (Fig. 5 e).

\subsection{Testing specific delivery of phIL-15 In vitro}

To test effective EP conditions obtained from the GFP experiments; we next delivered phIL-15 into the 3D tumor model and compared transfection efficiencies to the GFP experiments. The goal was to translate the most effective EP conditions and expression kinetics into in vivo studies. The spheroids were injected and simultaneously electroporated with phIL-15 + B16.F10 (Fig. 6). Both the spheroid and the media were collected after 24$48 \mathrm{~h}$ and tested for hIL-15 protein production by ELISA analysis. Expression levels of hIL-15 were compared between the $\mathrm{HaCaT}$ alone and $\mathrm{HaCaT}+\mathrm{B} 16$.F10 spheroids under the following delivery conditions: 1) control, 2) phIL-15 injection alone, 3) phIL-15 + HVSP and 4) phIL-15 + LVLP. Fold-changes between groups were calculated and the results were utilized to compare experimental groups to $\mathrm{HaCaT}$ control or $\mathrm{HaCaT}$ phIL-15 injection only groups. Low levels of hIL-15 expression were detected in HaCaT spheroid (absent of B16.F10 cells) lysate in the injection only, phIL-15 + HVSP and phIL-15 + LVLP groups. Higher levels of IL-15 were detected in the HaCaT + B16.F10 phIL-15 + HVSP and $\mathrm{HaCaT}+\mathrm{B} 16 . \mathrm{F} 10$ phIL-15 + LVLP groups. The HaCaT + B16.F10 phIL-15 + LVLP group demonstrated significant 3.0-fold and 4.1-fold expression increase at $24 \mathrm{~h}$ and $48 \mathrm{~h}$, respectively (Fig. 6a). The media which contained the spheroids during EP and subsequent incubation was also tested. For the spheroids containing only $\mathrm{HaCaT}$ cells, we observed a 1.3-fold increase in the phIL-15 + HVSP group and 2.6-fold from phIL-15 + LVLP group at $24 \mathrm{~h}$. For the media collected from the HaCaT + B16.F10 spheroids, there was a slight increase in hIL-15 expression in the phIL-15 + HVSP group, while the phIL-15 + LVLP group demonstrated a significant 10.4-fold and 14.9-fold increase at $24 \mathrm{~h}$ and $48 \mathrm{~h}$, respectively (Fig. 6b). Overall hIL-15 expression levels were much higher in the melanoma cells than in the keratinocytes as observed in vitro. One interesting rationalization for this phenomenon is loosely suspended B16.F10 cells injected into a spheroid were more likely to be transfected with plasmid using the 6-PEor 6-needle electrode conditions than tightly organized $\mathrm{HaCaT}$ cells forming a less permeable barrier [7]. In addition, investigators have reported that electric fields fired in multiple directions within a tissue increases the number of cells that are permeabilized [6,7,22-25,34,35]. Therefore, based on our experiments, loosely adherent B16.F10 cells exposed to the multi-directional electric field of the 6-PE were more likely to take up the plasmid than highly adherent HaCaT cells. 


\subsection{Comparing transfection Efficiencies of phlL-15 delivery in vivo}

The delivery of plasmids in vitro to a monolayer of cells is not representative of the delivery process in vivo. We predicted that the 3D model would serve as a good indicator to characterize phIL-15 transfection efficacy and could then utilize this information to translate effective delivery conditions in vivo. For these studies, we used C57BL/6 mice to test EP delivery parameters on skin and tumor sites at different time points (Fig. 7). Intradermal delivery using a 4-PE showed a 1.9-fold increase of hIL-15 at $12 \mathrm{~h}$ and 17.9-fold increase at $18 \mathrm{~h}$ in group phIL-15 + EP with eight $150 \mathrm{~ms}$ pulses at $100 \mathrm{~V} / \mathrm{cm}$, while phIL-15 + EP with eight $20 \mathrm{~ms}$ pulses at $200 \mathrm{~V} / \mathrm{cm}$ showed a 2.6 -fold increase at $12 \mathrm{~h}$ and 38.2 -fold increase at $18 \mathrm{~h}$ compared to intradermal phIL-15 injection without EP. Intratumoral delivery using a 6needle penetrating electrode (similar to 6-PE in vitro) delivering phIL-15 + EP with six 20 $\mathrm{ms}$ pulses at $500 \mathrm{~V} / \mathrm{cm}$ showed significant 8.9 -fold increase at $12 \mathrm{~h}$ and 9.2 -fold increase at $18 \mathrm{~h}$ compared to tumor phIL-15 injection. Intratumor delivery of phIL-15 + EP with six $100 \mu$ s pulses at $1300 \mathrm{~V} / \mathrm{cm}$ although not statistically significant, demonstrated the highest expression at $12 \mathrm{~h}$ with 4.7 -fold and 4.8 -fold increase at $18 \mathrm{~h}$ compared to intratumoral phIL-15 injection without EP. The results obtained indicated a difference in transfection efficacy between skin and tumor as well as differences in when different EP parameter sets were used. These findings were similar to those observed with the in vitro 3D studies (Figs. 6 and 7). Based on these observations, the EP parameters that stimulated high levels of IL-15 expression in the skin were $200 \mathrm{~V} / \mathrm{cm}, 20 \mathrm{~ms}$ pulses at $18 \mathrm{~h}$ and in the tumor were 500 $\mathrm{V} / \mathrm{cm}, 20 \mathrm{~ms}$ pulses at $12 \mathrm{~h}$. Interestingly, a decrease in expression of IL-15 was observed in the in vivo setting but not in the in vitro model. Since in vivo, there is an active immune system, it is possible that the delivery of phIL-15 to the tumor resulted in some cell death which reduced the expression. An additional possibility is that since IL-15 expression is highly controlled by many regulatory factors in vivo, the resulting IL-15 protein expression is short-lived [36]. The results observed with the in vitro 3D model supports this as a reduction of IL-15 expression, which was not seen in vitro in the absence of these in vivo factors $[37,38]$.

\section{Conclusions}

Skin and tumor cell types together can serve as a useful 3D tumor model that can be used to establish gene delivery techniques for translation to in vivo applications. In the studies reported here, we addressed the types of cellular signaling experienced from two different cell populations when introduced into a large-scale, free-floating 3D tumor model, in hopes of understanding how to link the biology of cells grown in culture to naturally occurring cells in the body. The development of such a practical and stable organotypic 3D tumor model could serve as a useful tool in the field of tissue engineering that may predict the outcomes of applications designed for in vivo studies. The ability of keratinocyte and melanoma cells to undergo signaling interactions such as proliferation, differentiation, and cross talk communication while residing in the spheroid is indicative of cells' ability to mimic functional properties in vivo. Furthermore, the information gathered from this in vitro 3D tumor model may benefit future studies, allowing exploration of many in vivo processes such as examining independent pathway systems to understand regulatory signaling before translating to studies in vivo.

\section{Supplementary Material}

Refer to Web version on PubMed Central for supplementary material. 


\section{Acknowledgments}

The research was supported by National Institute of Health, National Cancer Institute Fellowship Grant 5F31CA119950-01A2 and National Cancer Institute grant R01 CA122518.

The authors would like to thank Larry D. Sanford Ph.D., Frank A. Lattanzio Ph.D., Dr. Marta Ambrozewic Ph.D. of Eastern Virginia Medical School Norfolk, VA for providing access to cryostats, Charlie Szekeres Ph.D. University of South Florida Tampa, FL, Shawna Shirley Ph.D., and Diane Jackson D.V.M. from Old Dominion University Norfolk, VA for flow analysis recommendations and Diane Jackson D.V.M. for confirming HaCaT transfection efficiencies in vitro. Frank Reidy Research Center for Bioelectrics, ODU, Norfolk, VA for providing the inverted Olympic microscopes and FACS ARIA I for personal analysis. Bernadette Ferraro Ph.D. University of Pennsylvania, Philadelphia, PA for statistical analysis recommendations

\section{References}

1. Becker JL, Blanchard DK. Characterization of primary breast carcinomas grown in threedimensional cultures. J Surg Res. 2007; 142:256-262. [PubMed: 17727885]

2. Yamada KM, Cukierman E. Modeling tissue morphogenesis and cancer in 3D. Cell. 2007; 130:601610. [PubMed: 17719539]

3. Pickl M, Ries CH. Comparison of 3D and 2D tumor models reveals enhanced HER2 activation in 3D associated with an increased response to trastuzumab. Oncogene. 2009; 28:461-468. [PubMed: 18978815]

4. Schoop VM, Mirancea N, Fusenig NE. Epidermal organization and differentiation of HaCaT keratinocytes in organotypic coculture with human dermal fibroblasts. J Invest Dermato. 1999; 112:343-353.

5. Hutmacher DW, Loessner D, Rizzi S, Kaplan DL, Mooney DJ, Clements JA. Can tissue engineering concepts advance tumor biology research? Trends Biotechnol. 2010; 28:125-133. [PubMed: 20056286]

6. Wasungu L, Escoffre JM, Valette A, Teissie J, Rols MP. A 3D in vitro spheroid model as a way to study the mechanisms of electroporation. Int J Pharm. 2009; 379(2):278-284. [PubMed: 19716035]

7. Chopinet L, Wasungu L, Rols MP. First explanations for differences in electrotransfection efficiency in vitro and in vivo using spheroid model. Int J Pharm. 2011 Apr 28. [Epub ahead of print].

8. Haass NK, Smalley KS, Li L, Herlyn M. Adhesion, migration and communication in melanocytes and melanoma. Pigment Cell Res. 2005; 18:150-159. [PubMed: 15892711]

9. Smalley KS, Brafford PA, Herlyn M. Selective evolutionary pressure from the tissue microenvironment drives tumor progression. Semin Cancer Biol. 2005; 15:451-459. [PubMed: 16043361]

10. Marrero B, Messina JL, Heller R. Generation of a tumor spheroid in a microgravity environment as a 3D model of melanoma. In Vitro Cell Dev Biol Anim. 2009; 45:523-534. [PubMed: 19533253]

11. Deyrieux AF, Wilson VG. In vitro culture conditions to study keratinocyte differentiation using the HaCaT cell line. Cytotechnology. 2007; 54:77-83. [PubMed: 19003021]

12. Szell M, Bata-Csorgo Z, Koreck A, Pivarcsi A, Polyanka H, Szeg C, et al. Proliferating keratinocytes are putative sources of the psoriasis susceptibility-related EDA+ (extra domain A of fibronectin) oncofetal fibronectin. J Invest Dermatol. 2004; 123:537-546. [PubMed: 15304094]

13. Tajima S, Ura-Ishiko A, Hayashi A. Melanogenesis, biosynthetic phenotype of fibronectin and collagen, and migrating activity in cloned B16 mouse melanoma cells. J Dermatol Sci. 1996; 12:24-30. [PubMed: 8740457]

14. Gaggioli C, Deckert M, Robert G, Abbe P, Batoz M, Ehrengruber MU, et al. HGF induces fibronectin matrix synthesis in melanoma cells through MAP kinase-dependent signaling pathway and induction of Egr-1. Oncogene. 2005; 24:1423-1433. [PubMed: 15608673]

15. Ong SM, Zhao Z, Arooz T, Zhao D, Zhang S, Du T, et al. Engineering a scaffold-free 3D tumor model for in vitro drug penetration studies. Biomaterials. 2010; 31:1180-1190. [PubMed: 19889455] 
16. Kelm JM, Timmins NE, Brown CJ, Fussenegger M, Nielsen LK. Method for generation of homogeneous multicellular tumor spheroids applicable to a wide variety of cell types. Biotechnol Bioeng. 2003; 83(2):173-180. [PubMed: 12768623]

17. Feder-Mengus C, Ghosh S, Reschner A, Martin I, Spagnoli GC. New dimensions in tumor immunology: what does 3D culture reveal? Trends Mol Med. 2008; 14:333-340. [PubMed: 18614399]

18. Smalley KS, Brafford P, Haass NK, Brandner JM, Brown E, Herlyn M. Up-regulated expression of zonula occludens protein-1 in human melanoma associates with $\mathrm{N}$-cadherin and contributes to invasion and adhesion. Am J Pathol. 2005; 166:1541-1554. [PubMed: 15855653]

19. Dongari-Bagtzoglou A, Kashleva H. Development of a highly reproducible three-dimensional organotypic model of the oral mucosa. Nat Protoc. 2006; 1:2012-2018. [PubMed: 17487190]

20. Hsu MY, Meier FE, Nesbit M, Hsu JY, Van Belle P, Elder DE, et al. E-cadherin expression in melanoma cells restores keratinocyte-mediated growth control and down-regulates expression of invasion-related adhesion receptors. Am J Pathol. 2000; 156:1515-1525. [PubMed: 10793063]

21. Smalley KS. A pivotal role for ERK in the oncogenic behaviour of malignant melanoma? Int $\mathrm{J}$ Cancer. 2003; 104:527-532. [PubMed: 12594806]

22. Heller LC, Heller R. In vivo electroporation for genetherapy. Hum Gene Ther. 2006; 17(9):890897. [PubMed: 16972757]

23. Heller LC, Jaroszeski MJ, Coppola D, McCray AN, Hickey J, Heller R. Optimization of cutaneous electrically mediated plasmid DNA delivery using novel electrode. Gene Ther. 2007; 14(3):275280. [PubMed: 16988718]

24. Gilbert RA, Jaroszeski MJ, Heller R. Novel electrode designs for electrochemotherapy. Biochim Biophys Acta. 1997; 1334(1):9-14. [PubMed: 9042358]

25. Cheng C, Tennenbaum T, Dempsey PJ, Coffey RJ, Yuspa SH, Dlugosz AA. Epidermal growth factor receptor ligands regulate keratin 8 expression in keratinocytes, and transforming growth factor alpha mediates the induction of keratin 8 by the v-rasHa oncogene. Cell Growth Differ. 1993; 4:317-327. [PubMed: 7684248]

26. Kuwahara M, Hatoko M, Tada H, Tanaka A. E-cadherin expression in wound healing of mouse skin. J Cutan Pathol. 2001; 28:191-199. [PubMed: 11426826]

27. Boelsma E, Verhoeven MC, Ponec M. Reconstruction of a human skin equivalent using a spontaneously transformed keratinocyte cell line (HaCaT). J Invest Dermatol. 1999; 112:489-498. [PubMed: 10201534]

28. Stoler AB, Stenback F, Balmain A. The conversion of mouse skin squamous cell carcinomas to spindle cell carcinomas is a recessive event. J Cell Biol. 1993; 122:1103-1117. [PubMed: 7689080]

29. Wang R, Xu J, Juliette L, Castilleja A, Love J, Sung SY, et al. Three-dimensional co-culture models to study prostate cancer growth, progression, and metastasis to bone. Semin Cancer Biol. 2005; 15:353-364. [PubMed: 15982899]

30. Tang A, Eller MS, Hara M, Yaar M, Hirohashi S, Gilchrest BA. E-cadherin is the major mediator of human melanocyte adhesion to keratinocytes in vitro. J Cell Sci. 1994; 107:983-992. [PubMed: 8056851]

31. Delehedde M, Cho SH, Hamm R, Brisbay S, Ananthaswamy HN, Kripke M, et al. Impact of Bcl-2 and Ha-ras on keratinocytes in organotypic culture. J Invest Dermatol. 2001; 116:366-373. [PubMed: 11231309]

32. Lemaitre G, Lamartine J, Pitaval A, Vaigot P, Garin J, Bouet S, et al. Expression profiling of genes and proteins in $\mathrm{HaCaT}$ keratinocytes: proliferating versus differentiated state. J Cell Biochem. 2004; 93:1048-1062. [PubMed: 15389883]

33. Lee SB, Schramme A, Doberstein K, Dummer R, Abdel-Bakky MS, Keller S, et al. ADAM10 is upregulated in melanoma metastasis compared with primary melanoma. J Invest Dermatol. 2010; 130:763-773. [PubMed: 19865098]

34. Lucas ML, Heller R. Immunomodulation by electrically enhanced delivery of plasmid DNA encoding IL-12 to murine skeletal muscle. Mol Ther. 2001; 3(1):47-53. [PubMed: 11162310] 
35. Lucas ML, Heller L, Coppola D, Heller R. IL-12 plasmid delivery by in vivo electroporation for the successful treatment of established subcutaneous B16.F10 melanoma. Mol Ther. 2002; 5:668675. [PubMed: 12027550]

36. Budagian V, Bulanova E, Paus R, Bulfone-Paus S. IL-15/IL-15 receptor biology: a guided tour through an expanding universe. Cytokine Growth Factor Rev. 2006; 17:259-280. [PubMed: 16815076]

37. Ruckert R, Asadullah K, Seifert M, Budagian VM, Arnold R, Trombotto C, et al. Inhibition of keratinocyte apoptosis by IL-15: a new parameter in the pathogenesis of psoriasis? J Immunol. 2000; 165:2240-2250. [PubMed: 10925312]

38. Maas-Szabowski N, Starker A, Fusenig NE. Epidermal tissue regeneration and stromal interaction in HaCaT cells is initiated by TGF-alpha. J Cell Sci. 2003; 116:2937-2948. [PubMed: 12771184] 

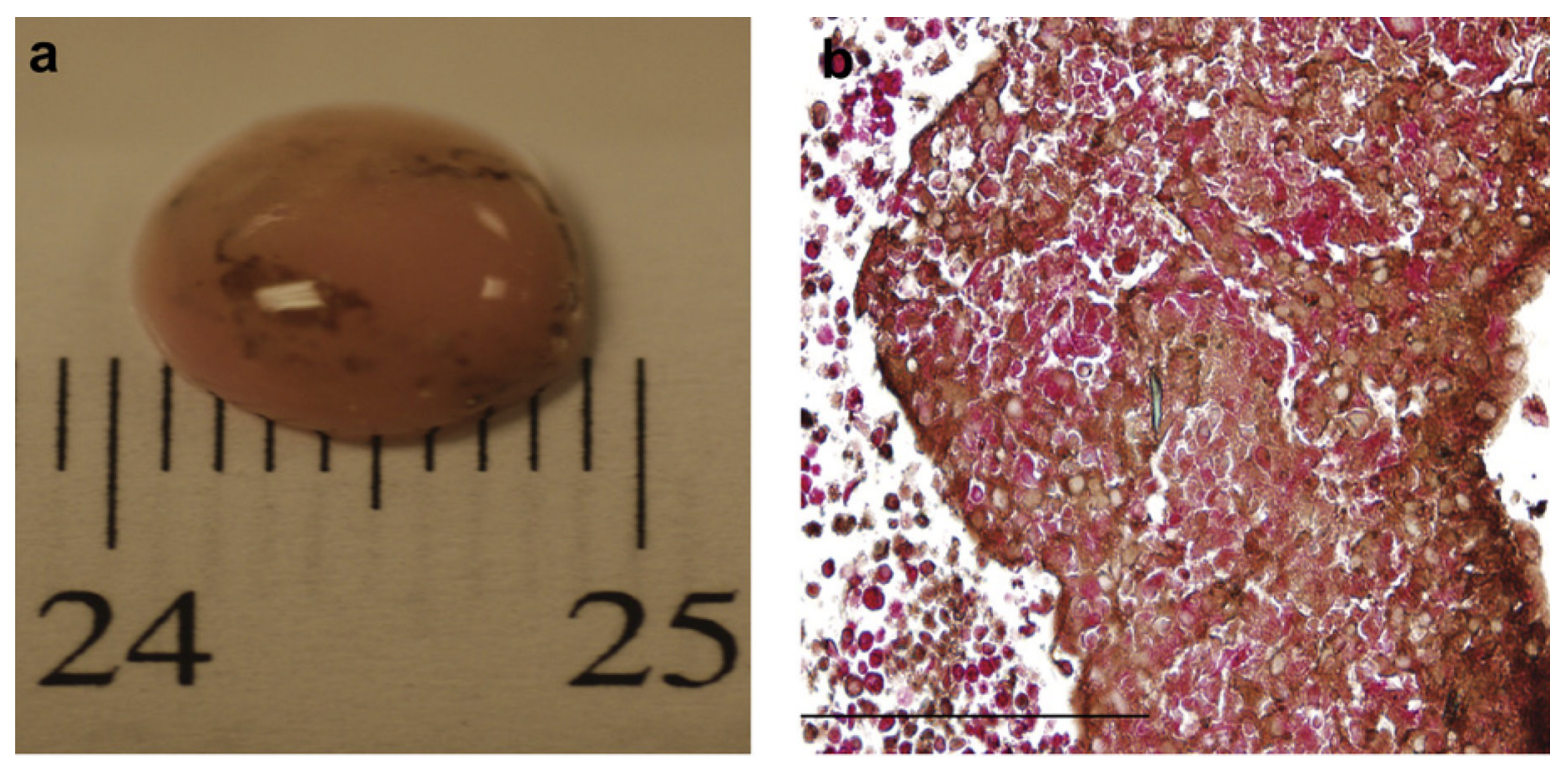

C

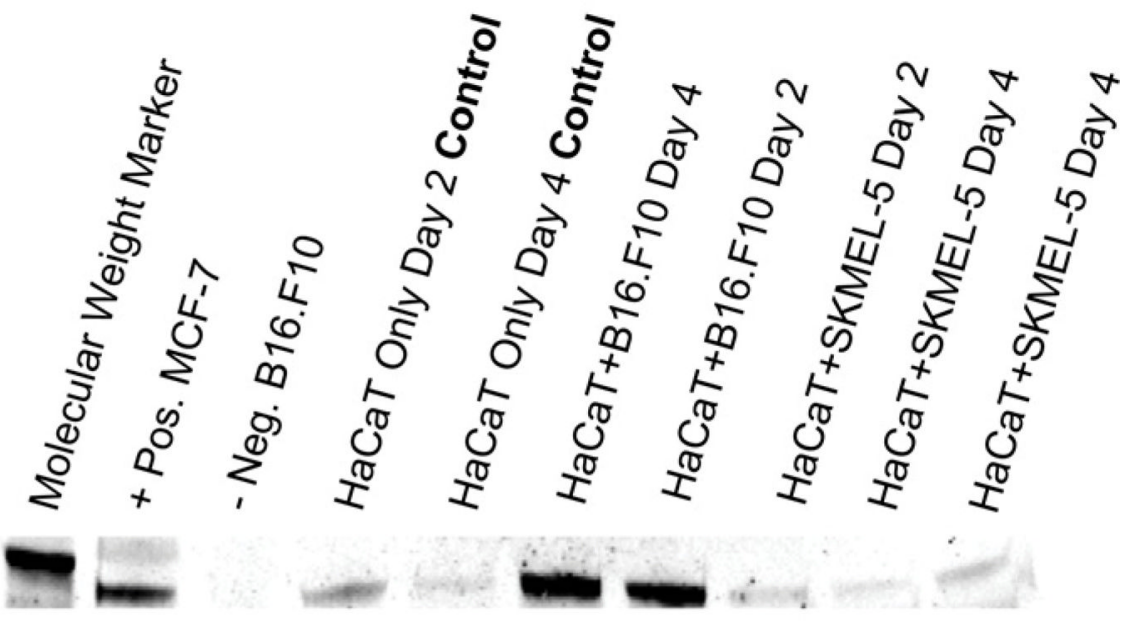

E-Cadherin 97kd

\section{$\begin{array}{lllllll}1 & 1 & 1.9 & 2.3 & 0.9 & 0.6 & 0.7\end{array}$}

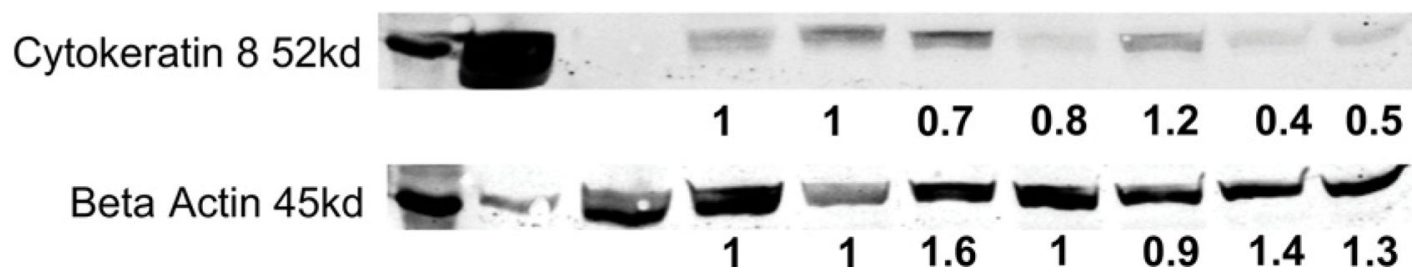

Fig. 1.

The 3D spheroid forms a stable and functional tumor model. (a) $50 \times 10^{6} \mathrm{HaCaT}$ cells injected into the HARV formed a stable spheroid within 1-2 days. The spheroids injected with $3 \times 10^{6}$ of B16.F10 [10] or SKMEL-5 cells formed a tumor spheroid within 6 days. Each experiment was performed at least 3 times. (b) Viability of $\mathrm{HaCaT}$ injected with SKMEL was tested using a TdT assay. Each experiment was performed at least 3 times. Magnification (Mag) 400×. (c) Western blot analysis was used to test the functionality of cells residing in the 3D model. HaCaT, HaCaT + B16.F10 and HaCaT+SKMEL-5 were immunoblotted for the presence of E-cad and Cyto-8 proteins on days 2 and 4 . Positive control MCF-7 breast cancer cells and negative control B16.F10 cell lysate tested the 
specificity of primary antibody proteins markers E-cad and Cyto-8. Supernatant of spheroid lysate was normalized by BCA Protein assay kit and $32 \mu \mathrm{g}$ of total protein was loaded into the wells of the gel. All samples were normalized against Beta Actin and fold change was determined by densitometry analysis comparing band density to HaCaT only control group on days 2 and 4, using Quant one software. WB experiments were performed at least 6 times. Scale bars, $1 \mathrm{~cm}$ (a); $200 \mu \mathrm{m}$ (b). 

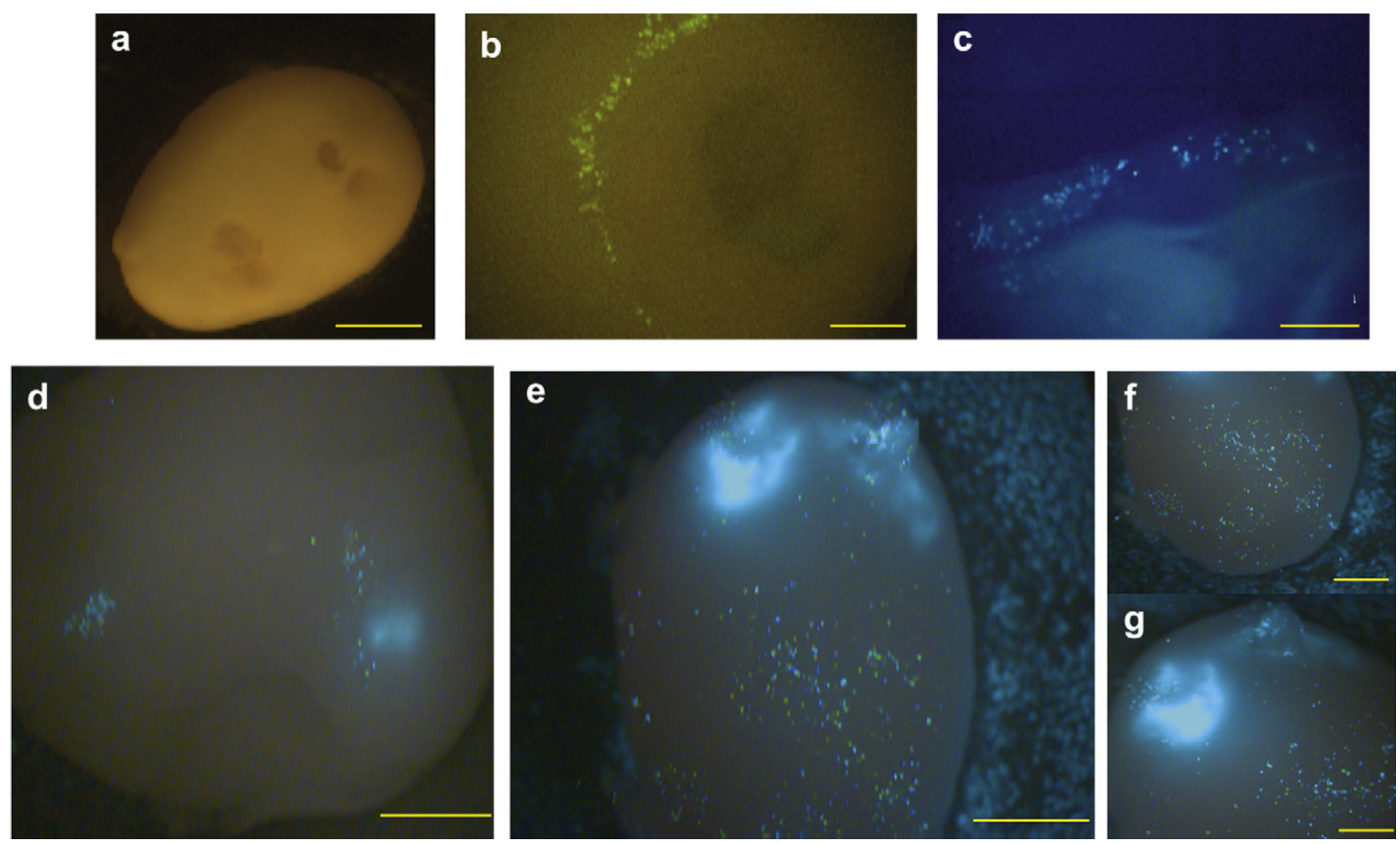

Fig. 2.

Delivery of pEGFP-N1 into spheroids using EP enhances GFP expression. (a) A stable $\mathrm{HaCaT}$ spheroid formed after 2 days was injected with pEGFP-N1 and EP was performed using a 4-needle electrode applying twelve $150 \mathrm{~ms}$ pulses at $100 \mathrm{~V} / \mathrm{cm}$ to observe GFP expression. Mag 16×. (b) This HaCaT spheroid was analyzed $24 \mathrm{~h}$ after transfection to observe GFP expression. Mag 80×. (c) The HaCaT spheroid injected with pEGFP-N1 and EP with 4-PE applying eight $20 \mathrm{~ms}$ pulses at $200 \mathrm{~V} / \mathrm{cm}$, was harvested after $24 \mathrm{~h}$. GFP expression was found near the external surface. Mag 48×. (d) HaCaT spheroid simultaneously injected with $50 \mu \mathrm{l} 1.0 \mathrm{mg} / \mathrm{ml}$ pEGFP-N1, 3-5 ×106 B16.F10 and electroporated with six $100 \mu$ s pulses at $1300 \mathrm{~V} / \mathrm{cm}$ applied with the 6-PE. Analyzed was performed after $24 \mathrm{~h}$. Mag 32×. (e) HaCaT spheroid simultaneously injected with $50 \mu \mathrm{l}$ of $1.0 \mathrm{mg} / \mathrm{ml}$ pEGFP-N1, 3-5 × $10^{6}$ B16.F10 and electroporated with six $20 \mathrm{~ms}$ pulses at 500 $\mathrm{V} / \mathrm{cm}$ applied using the 6-PE. Analysis was performed after $24 \mathrm{~h}$. Mag 32×. (f) Expression was observed proximal to the site of injection. Mag 40x and (g) Distal site of injection Mag $40 \times$. Images were representative of 5 experiments. Scale bars, $2 \mathrm{~mm}$ (a,d,e); $1 \mathrm{~mm}$ (b,c,f,g). 


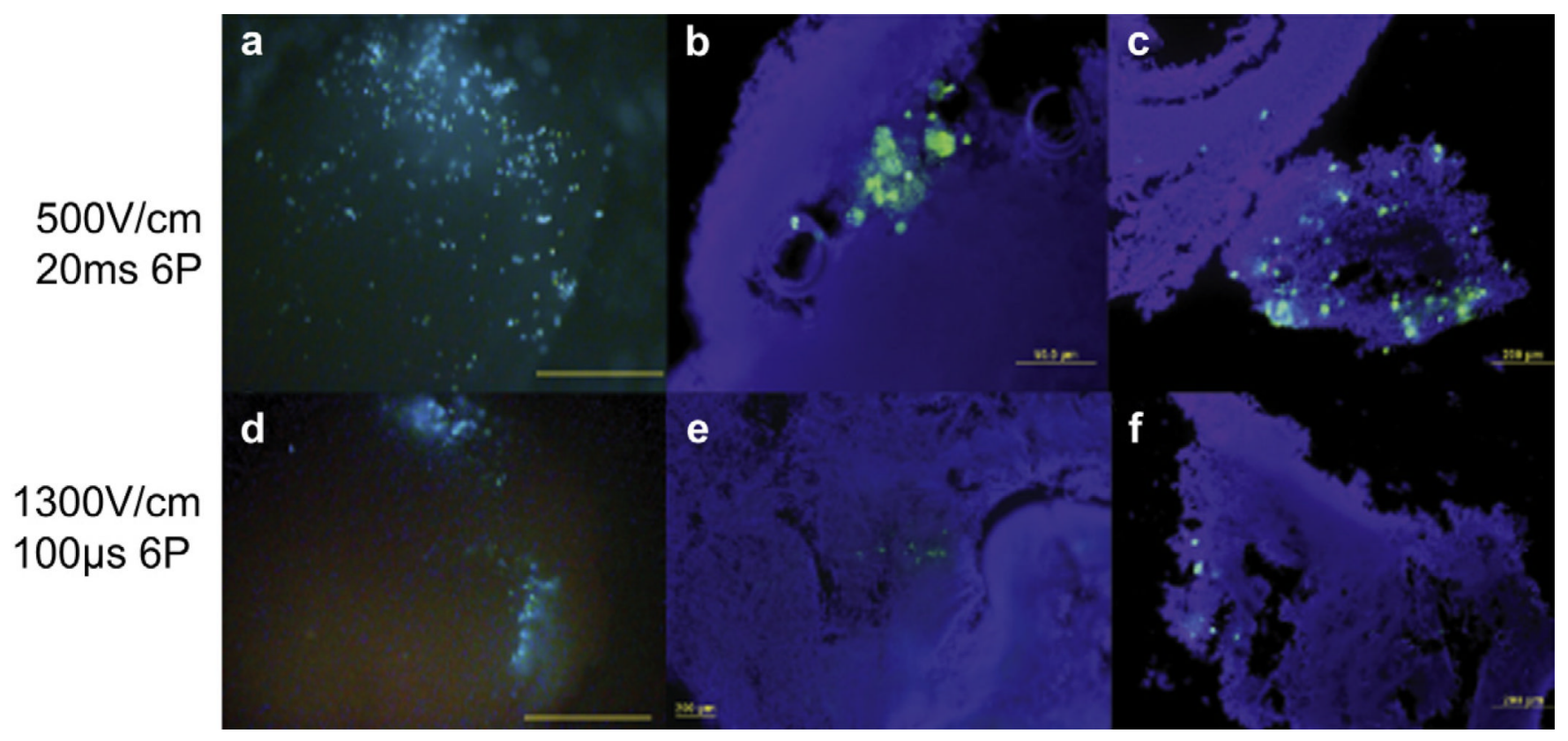

Fig. 3.

GFP distribution in 3D tumor model. (a) Analysis of GFP distribution from the LVLP group used to facilitate delivery of pEGFP-N1 into a $0.8-1.0 \mathrm{~cm}$ spheroid containing $\mathrm{HaCaT}+$ B16.F10. Spheroid samples were collected $24 \mathrm{~h}$ after transfection, Mag 32×. (b-c) Cryosection analysis of HaCaT + B16.F10 transfected with pEGFP-N1 at LVLP, for contrast the nuclei were labeled with DAPI. (d) EP analysis of GFP distribution from HVSP group was used to deliver pEGFP-N1 into a spheroid containing HaCaT + B16.F10. Mag 32×. (e-f) Cryo-section analysis of HaCaT + B16.F10 transfected with pEGFP-N1 with HVSP. An Olympus (Center Valley, PA) microscope with camera was used to capture images at Mag. 200x. Sections were cut $8-10 \mu \mathrm{m}$ thick. These images are representative of 2 out of 5 experiments performed $n=8-10$ per group. Scale bars, $2 \mathrm{~mm}$ (a,d); $50 \mu \mathrm{m}$ (b); $200 \mu \mathrm{m}$ (c,e.f). 


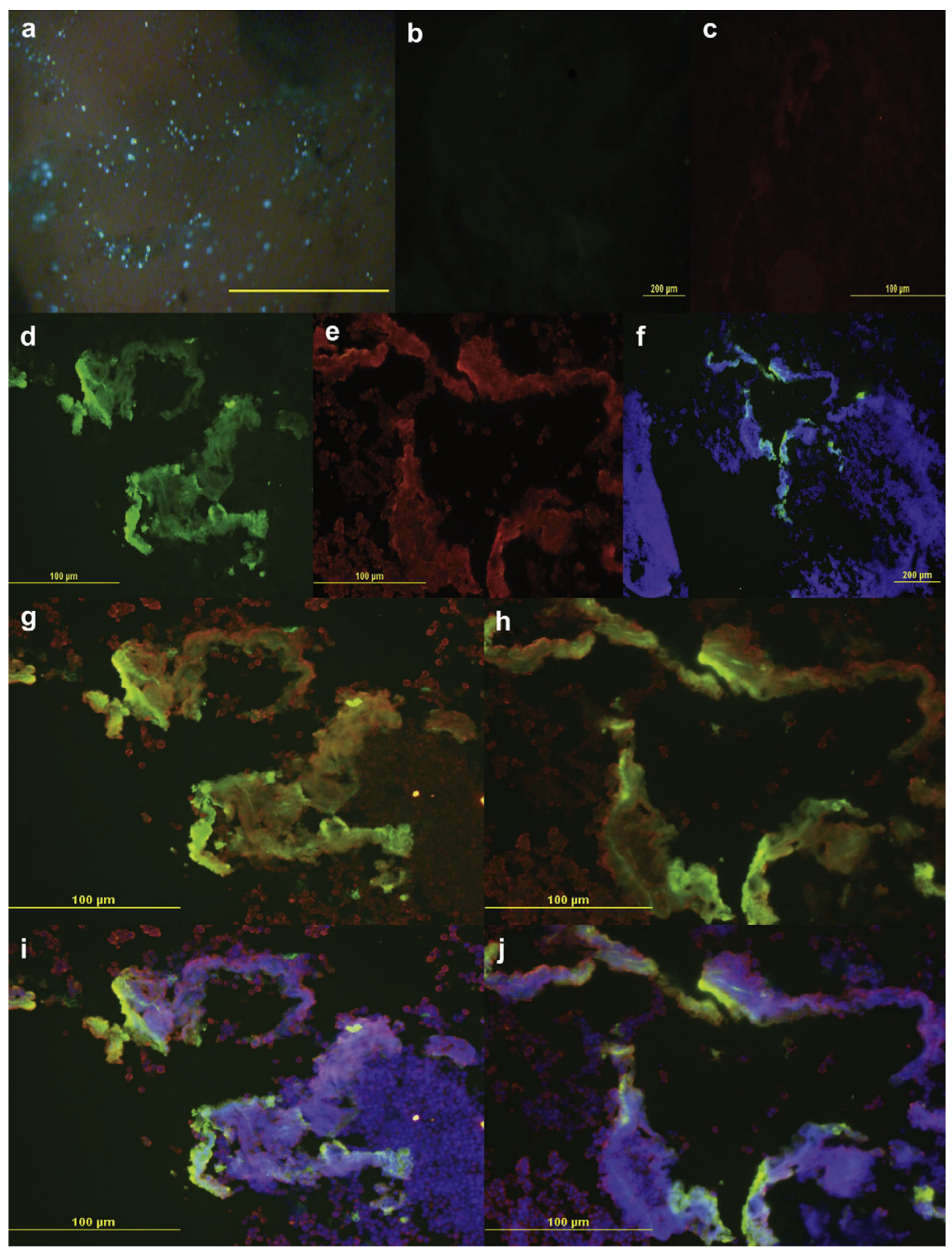

Fig. 4.

GFP expression analysis in 3D tumor model. Efficiency of pEGFP-N1 delivery was analyzed by fluorescence imaging and showed increased GFP distribution when delivered with the 6PE using LVLP parameters after $24 \mathrm{~h}(\mathrm{a}-\mathrm{j})$. (a) Stereomicroscope image of a 0.8$1.0 \mathrm{~cm} \mathrm{HaCaT}$ spheroid + B16.F10. Melanoma cells were indicated by dark brown spots, $\mathrm{HaCaT}$ cells were indicated by a tan color and successfully transfected cells produced green fluorescence. Mag 96×. (b) Negative control FITC channel tested non-specific secondary binding in the absence of primary antibody. (c) Negative control in the TRITC channel. (d) GFP expression alone in the FITC channel. (e) Cytokeratin AE1/3 rhodamine antibody specifically labeled HaCaT, visualized in the TRITC channel. (f) Merged image of DAPI 
blue and GFP green channels. (g-h) Merged image GFP green, DAPI blue, and Cytokeratin red channels; overlay of images produced a yellow or orange fluorecence, HaCaT cells lacking GFP expression appeared red and GFP expressing B16.F10 cells appeared green. (ij) Overlay of red $\mathrm{HaCaT}$ and green GFP produced a orange fluorescence signifying that HaCaT were labeled, while yellow or green specified B16.F10 cells expressing GFP. An Olympus BX51 microscope with camera was used to take pictures at Mag 100× (f) and $200 \times(b-e, g-j)$. Sections were cut 8-10 $\mu \mathrm{m}$ thick; images are a representation $8-10$ experiments performed. Scale bars, $2 \mathrm{~mm}(\mathrm{a}) ; 200 \mu \mathrm{m}$ (b,f); $100 \mu \mathrm{m}$ (c-e, g-j). (For interpretation of the references to colour in this figure legend, the reader is referred to the web version of this article.) 

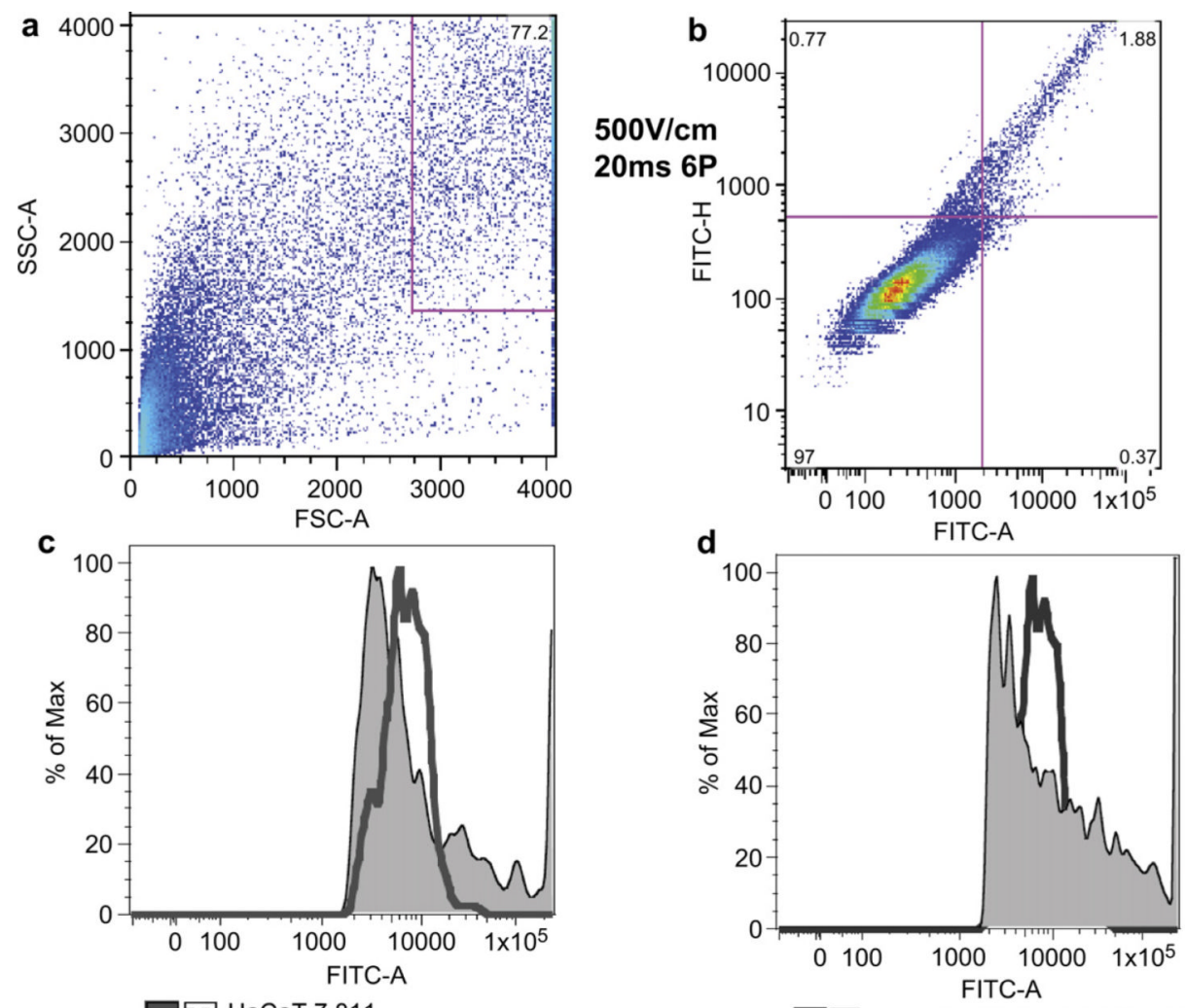

I. $\mathrm{HaCaT} 7,811$

曰 $\mathrm{HaCaT+B16.F10} 1300 \mathrm{~V} / \mathrm{cm} 32,882$

$\mathrm{HaCaT}+\mathrm{B} 16 . \mathrm{F} 10500 \mathrm{~V} / \mathrm{cm} 52,963$

.7. $\mathrm{HaCaT} 7,811$

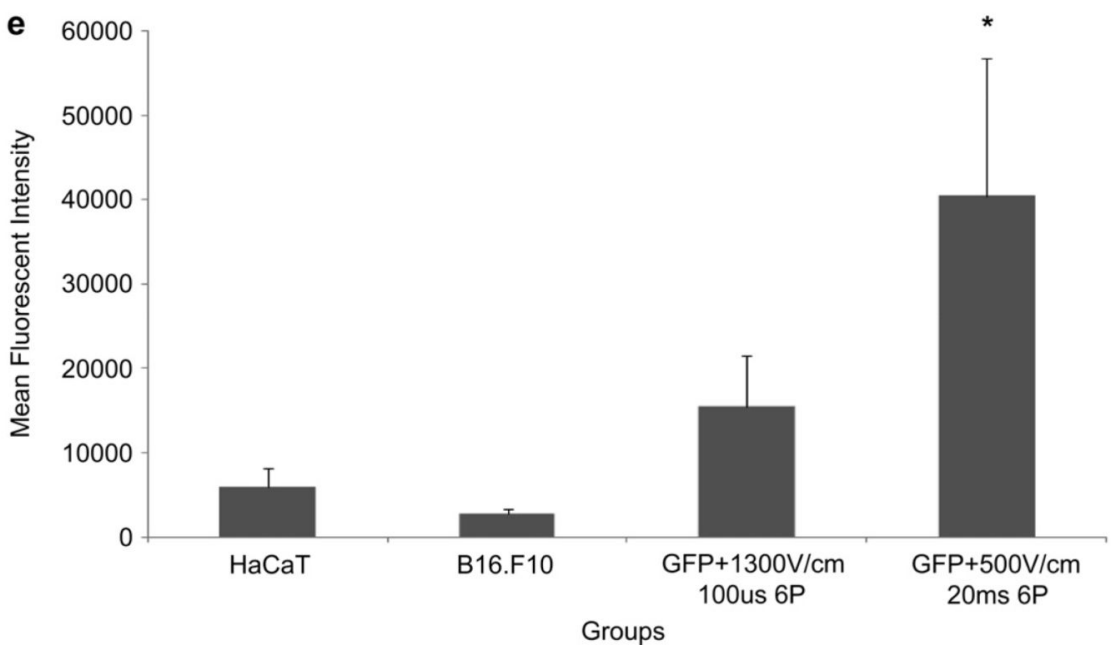

Fig. 5.

Flow cytometry quantifies high levels of GFP expression from $\mathrm{HaCaT}+\mathrm{B} 16 . \mathrm{F} 10$ spheroids transfected with pEGFP-N1 after $24 \mathrm{~h}$. The spheroids were pressed through a $40 \mu \mathrm{m}$ nylon screen, collected, and evaluated for viability using trypan blue exclusion. Cells were labeled with propidium iodide to gate live cells. FlowJo software was used to analyze flow data. (a) Events recorded for P1 gate 113,290 cells, showing location of HaCaT + B16F10 cells (77.2\%). (b) Quadratic gate divided 87,500 live cells into positive and negative populations and presence or absent of GFP expression. In quadrant 2, pEGFP-N1 transfected cells showed $1.88 \%$ expression (Additional P1 and Q were analyzed in Supplementary material online Fig. 1). (c) One-dimensional histograms measures average MFI in HaCaT and HaCaT 
+ B16.F10 + HVSP groups, demonstrating a 4.2-fold increase in GFP expression. (d) Histogram shows overlapping $\mathrm{HaCaT}$ control with $\mathrm{HaCaT}+\mathrm{B} 16 . \mathrm{F} 10 \mathrm{EP}$ at $500 \mathrm{~V} / \mathrm{cm}$ and 20 ms demonstrating a 6.8-fold increase in GFP expression. (e) Graphical representation of all GFP MFIs analyzed from 4 independent experiments. HaCaT + B16.F10 + LVLP showed 6.8 -fold statistically significant $\left({ }^{*} p<0.001\right)$ increase in GFP compared to $\mathrm{HaCaT}$ control. HaCaT+16.F10 + HVSP showed an insignificant 2.6-fold increase compared to $\mathrm{HaCaT}$ control cells. Flow analysis readings were repeated in triplicates for each sample thus fold change varied between the readings. Error bars were measured as standard deviation between samples in the same group. (For interpretation of the references to colour in this figure legend, the reader is referred to the web version of this article.) 

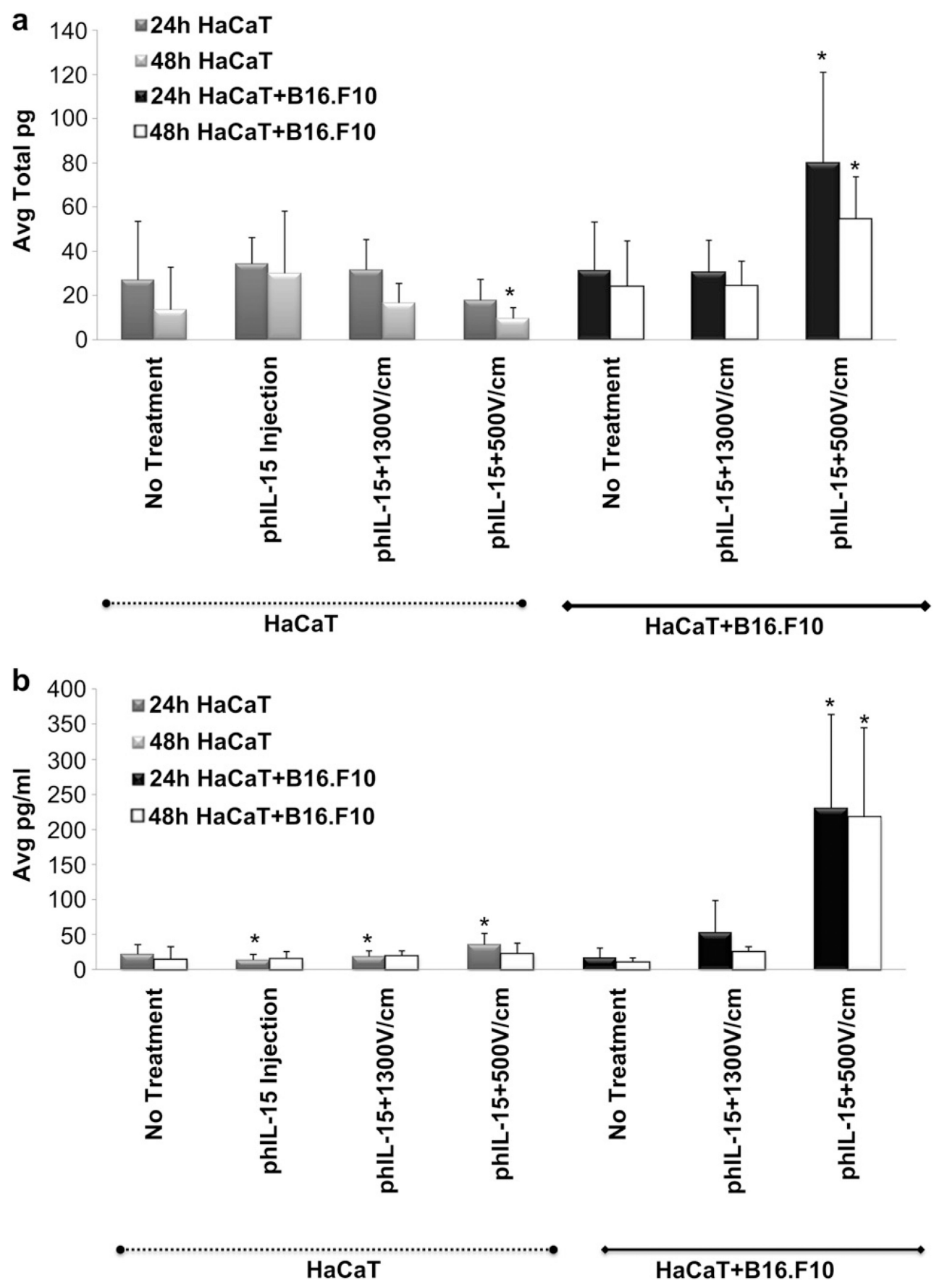

Fig. 6.

Delivery of phIL-15 into HaCaT alone and HaCaT + B16.F10 spheroids were analyzed after $24 \mathrm{~h}$ and $48 \mathrm{~h}$ by ELISA. (a) Delivery of phIL-15 into HaCaT groups on the left side of graph (dotted line) and delivery into HaCaT + B16.F10 groups on the right side of graph (solid line). Average total pg of protein expression was measured from spheroid lysate. The phIL-15 + LVLP used to deliver phIL-15 into HaCaT cells demonstrated a significant decrease of IL-15 production at $48 \mathrm{~h}(* p=<0.001)$. Moreover, HaCaT + B16.F10 showed significant 3.0-fold increase in phIL-15 + LVLP at $24 \mathrm{~h}$ and 4.1-fold at $48 \mathrm{~h}(* p=<0.001)$ compared to HaCaT control. (b) Delivery of phIL-15 into HaCaT (dotted line) and HaCaT + B16.F10 (solid line) measuring average $\mathrm{pg} / \mathrm{ml}$ of protein expression in the media. We found 
that $\mathrm{HaCaT}$ spheroids showed similarly low levels of hIL-15 expression in the media (b) as in the lysate (a). HaCaT HVSP had a 1.3 -fold increase at $24 \mathrm{~h}\left({ }^{*} p=0.050\right)$ and $\mathrm{HaCaT}$ phIL-15 + LVLP had a 2.6-fold increase at $24 \mathrm{~h}(* p=0.026)$ compared to the HaCaT phIL-15 injection only group. HaCaT + B16.F10 phIL-15 + LVLP increased 10.4-fold at 24 $\mathrm{h}(* p=0.027)$ and 14.9 -fold increase at $48 \mathrm{~h}(* p=0.001)$ compared to HaCaT control. Although HaCaT + B16.F10 phIL-15 + HVSP measurements were not considered significant, the expression levels had slight 2.3-fold increase at $24 \mathrm{~h}$ and 1.7 -fold increase of hIL-15 at $48 \mathrm{~h}$ compared to $\mathrm{HaCaT}$ control group. Error bars show standard deviation between samples in the same group. (a) 4-10 independent experiments were performed (b) 4-6 independent experiments were performed. 


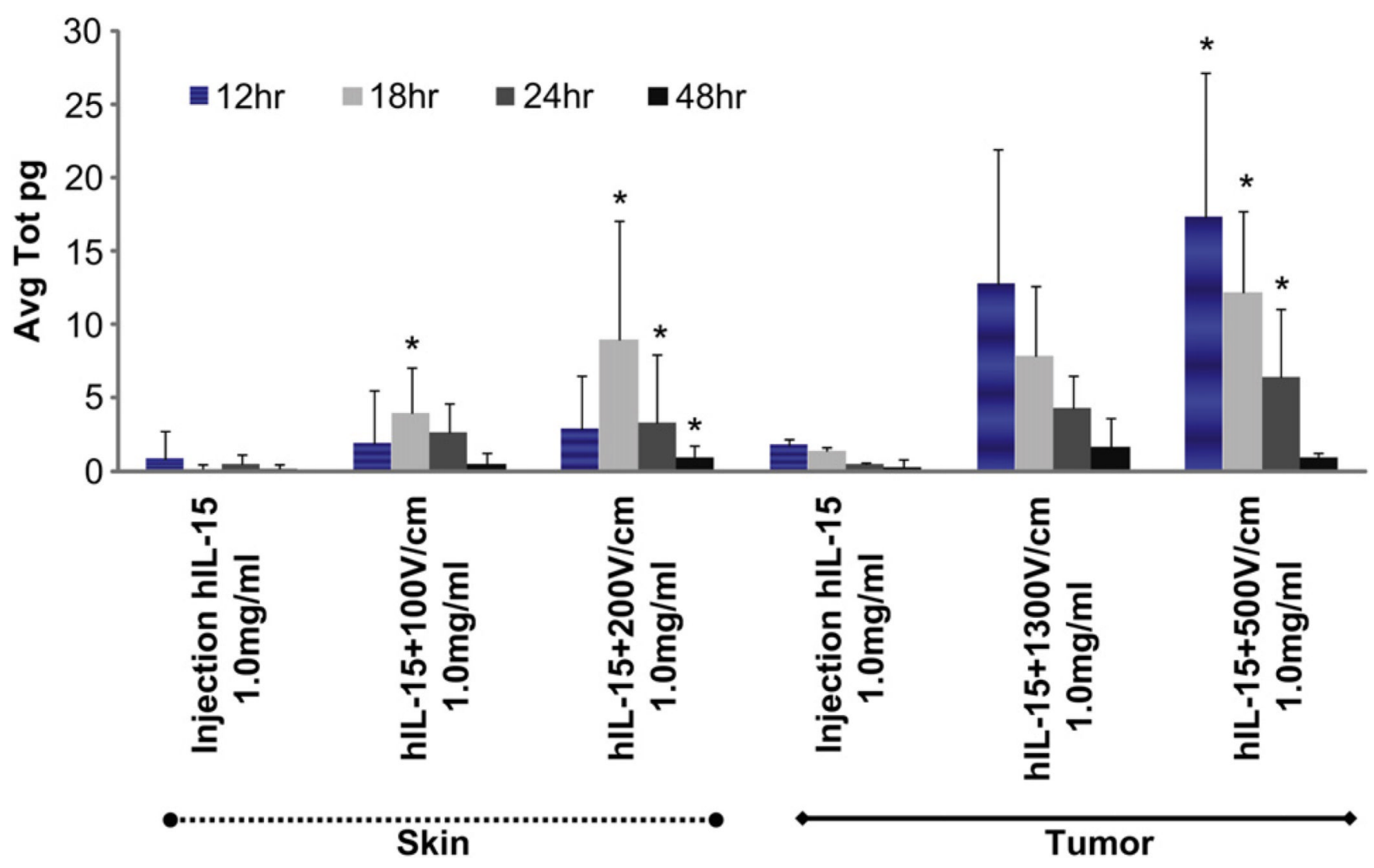

Fig. 7.

In vivo delivery of phIL 15 into tumor and skin compares favorably with delivery using the 3D tumor model. Expression of IL-15 was analyzed by ELISA. Tumor and skin samples were collected at $12 \mathrm{~h}, 18 \mathrm{~h}, 24 \mathrm{~h}$ and $48 \mathrm{~h}$. The skin samples are displayed as the first three groups (left side of graph, dotted line) and tumor samples are displayed as the last three groups (right side of graph, solid line). To reduce the number of mice used, delivery was performed to four skin sites on each mouse. Each site received a $50 \mu \mathrm{l}$ injection of $1 \mathrm{mg} / \mathrm{ml}$ phIL-15. Skin showed significant increase in hIL-15 expression in groups phIL-15 + HVSP, 17.9-fold $(* p=0.019)$ at $18 \mathrm{~h}$, phIL-15 + LVLP, 38.2-fold $(* p=<0.001)$ at $18 \mathrm{~h}, 5.2$-fold $(* p=0.025)$ at $24 \mathrm{~h}$, and $3.6-$ fold $(* p=0.017)$ at $48 \mathrm{~h}$ (dotted line). Mice containing one established tumor received a $50 \mu \mathrm{l}$ intratumoral injection of $1 \mathrm{mg} / \mathrm{ml} \mathrm{phIL}-15$. Significant results were observed with phIL-15 + LVLP, 8.9 -fold $(* p=0.026)$ at $12 \mathrm{~h}, 9.2$-fold $(* p=$ $0.006)$ at $18 \mathrm{~h}$, and 12.7 -fold $(* p=0.022)$ at $24 \mathrm{~h}$ (solid line). Error bars measured standard deviation between samples in the same group, $n=4$ tumor and $n=12$ skin samples, comparing three independent experiments. 


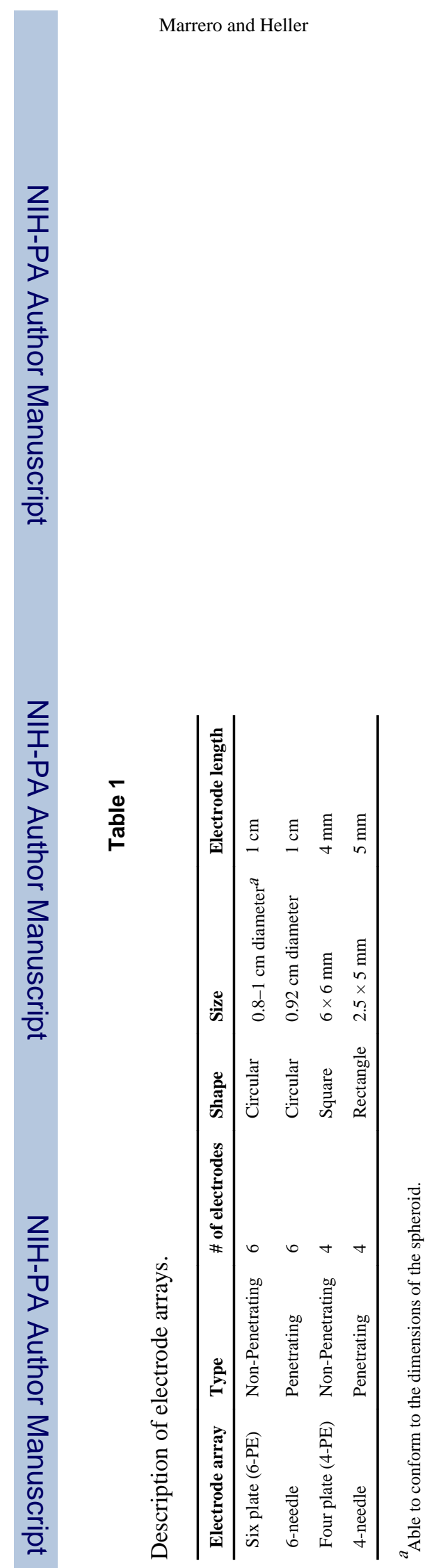

Page 25

Biomaterials. Author manuscript; available in PMC 2013 April 01. 